\title{
Estimation of Critical Gap Using Maximum Likelihood Method at Unsignalized Intersection: A Case Study in Adama City, Ethiopia
}

\author{
Fikedu Rage Faye \\ Department of Civil Engineering, Mettu University, Mettu, Ethiopia \\ Email address: \\ fikedu.rage@gmail.com \\ To cite this article: \\ Fikedu Rage Faye. Estimation of Critical Gap Using Maximum Likelihood Method at Unsignalized Intersection: A Case Study in Adama \\ City, Ethiopia. International Journal of Transportation Engineering and Technology. Vol. 7, No. 2, 2021, pp. 48-59. \\ doi: $10.11648 /$ j.ijtet.20210702.12
}

Received: May 29, 2021; Accepted: July 8, 2021; Published: July 15, 2021

\begin{abstract}
Studying Critical gap and headway distribution has vital role in reduction of traffic problems. Critical gap and its distribution are traffic characteristics that are used in determination of capacity, delay and level of service at unsignalized intersection. Many study has been done on critical gap in developed countries under homogeneous traffic and road conditions. This study is aimed to insight available headway distribution and critical gap of driver in urban intersection under heterogeneous traffic condition and weak lane discipline in developing country like Ethiopia. In this paper three unsignalized intersection in Adama city has been selected on the basis of traffic volume and importance of the intersection. The primary data that were used for this study were traffic volume, available headways, waiting time, geometry of road. By using digital Camera, videos data were recorded; later quantitative data were extracted from videos. Two Statistical Packages that were used in analysis of this study. Statistical Package for Social Science Statistic 20 was used to fit best distribution model of headway. Kolmogorov Smirnov and Anderson Darling testing techniques were conducted to check validity of model for headways in different flow ranges. From hypothesized distributions, exponential, gamma, lognormal and normal distributions were selected for different intersection. It has been indicated that, for higher flow rate lognormal distribution model is best fit in estimating cumulative density function of headway. Critical gaps of drivers for three selected intersections were also computed by using maximum likelihood method. Through Comparison of estimated values indicates that, Franko intersection has highest critical gap of $5.17 \mathrm{sec}$.
\end{abstract}

Keywords: Headway Distribution, Maneuver Type Maximum Likelihood, Waiting Time

\section{Introduction and Literature Review}

\subsection{Introduction}

Average follow-up headway and average critical headway are two key parameters in the new roundabout capacity model presented in the R. Morris, M. [14]. Study included statistical methodology for the estimation of the critical gap, and demonstrates its application through field measurements. It is assumed that the critical gap has a lognormal distribution among the driver population with a mean value that is a function of a number of explanatory variables. Based on these assumptions the critical gap and its distribution estimated using maximum likelihood. A case study in a dual lane roundabout in Stockholm is used to illustrate the proposed methodology using video and other data recording techniques. The results showed that the critical gap depends, among factors, on the target lane (near or far), the type of the vehicle and driver age [6]. Critical Gap for merging and crossing, factors that influences gap acceptances and waiting time to accept gaps were undermined in many studies in Ethiopia. So that the researcher is initiated to provide his own role by filling shortcoming of previous study concerning accessing available headway distribution and critical gap for drivers who are merging or crossing major road from minor road.

\subsection{Need of Present Study}

In ideal world where traffic flow is managed properly 
through traffic management system, where driver is design driver and other road users who can easily understand regulation of traffic rule, studying traffic characteristics like headway distribution, and critical headway, congestion, delay and level of service of intersection is not such mandatory. But since we live in real world transportation system problems and difficulties faces road users and policy makers from time to time. Despite we can minimize in systematic manner, we cannot avoid it. In Ethiopia there is a rapid increase in the number of the vehicles and their varieties which creates a headache for the transportation professionals and policy makers. As such type of traffic flow consists of a wide range of complex activities, embracing vehicle arrivals, speed of travel, lane discipline, un- necessary overtaking, mixed traffic flow and crossing logic, gap acceptance, waiting time, available headway, acceleration and deceleration. So that the researcher is initiated to put his own role by doing scientific research on headway distribution and available critical gaps which gives some understanding for road users (drivers, passengers and pedestrians) and professionals.

\subsection{Objective of Study}

The general objective of this study is to investigate distribution patterns of available headways to be accepted and rejected and also evaluate critical gaps that are available for the drivers in study in urban area.

\subsection{Review Literature}

A number of studies has been conducted on headways and critical gaps for the drivers. In this paper some studies which are more closely with study has been included. Time headway distribution is helpful to insight the disaggregate flow of traffic which is very important in capacity and level of service determination [10]. Video graphic data were collected for four road section in Assam city, later data were extracted and analyzed. The distribution of headways for different flow rates by increment of 200PCU/hr. also shown by Maurya, A. [13]. It has been shown Log Pearson-3 is best fit distribution for low flow rate up to $600 \mathrm{PCU} / \mathrm{hr}$. and Inverse Gaussian distribution for high flow rate greater than $800 \mathrm{PCU} / \mathrm{hr}$. Another study that was done in Oregon state university by Abd-Elaziz, A., \& Abd-Elwahab, S. [1], shows that non parametric approach to fit best distribution for headway. Using K-S test hypothesized distribution was rejected or accepted at 95 confidence interval. In this study headway distribution was made vehicle to vehicle interaction with their categories. Gaussian Kernel curve was developed and analyzed for selected interaction. The same study has been conducted in west Bengal city to show the headway distribution model by Abhishek, O., \& Marko A. A. Boon, R.-Q. [2] In India. Data were collected to observe time headways on a National Highway (two-lane highway) in the north-east India, popularly known as the Assam-Agartala road. A highway section of about $20 \mathrm{~km}$ length, close to the capital city. Data were captured ideographically. Based on collected data. Lognormal, Person 3P and Log logistics were selected model for different pair of traffic in category wise.

The method of Raff is based on macroscopic model and it is the earliest method for estimating the critical gap which is used in many countries because of its simplicity. This method involves the empirical distribution functions of accepted gaps $\mathrm{F}_{\mathrm{a}}(\mathrm{t})$ and rejected gaps $\operatorname{Fr}(\mathrm{t})$. When the sum of cumulative probabilities of accepted gaps and rejected gaps is to equal 1 then a gap of length tis equal to critical gap $\left(t_{c}\right)$. It means the number of rejected gaps larger than critical gap is equal to the number of accepted gaps smaller than critical gap. As Amin, H. J. [5] Empirical distribution accepted gap has been given by the following equation.

$$
F a(t)=1-F r(t)
$$

Where,

Fa: empirical distribution of accepted gap

Fr: empirical distribution of rejected gap

Dutta, M. M. [10] Used maximum likely hood method for estimating critical gaps was based on the Maximum likelihood method (MLM). The MLM is based on the assumption that minor stream drivers behave consistently. It means that each driver will reject every gap smaller than his critical gap and will accept the first gap larger than the critical gap. Under this assumption, the distribution of the critical gaps lies between distributions of largest rejected and accepted gaps. The parameters of distribution function of the critical gaps, the mean $(\mu)$ and variance $\left(\sigma^{2}\right)$ are obtained by maximizing the likelihood function by Akhilesh, M. K [3].

$$
L=\prod_{i=1}^{n}\left[F\left(a_{i}\right)-F\left(r_{i}\right)\right]
$$

Where, L: maximum likelihood function, $\mathrm{a}_{\mathrm{i}}$ : logarithm of the accepted gap of driver $i$,

ri: logarithm of the maximum rejected gap of driver

$\mathrm{F}\left(\mathrm{a}_{\mathrm{i}}\right)$ and $\mathrm{F}(\mathrm{ri})$ : cumulative distribution functions for the normal distribution.

Al-Obaed [4] Estimated critical gaps by nine important methods Raff, Wu, Logit, Ashworth, Lag, and Harder, Acceptance curve, clearing behavior, Green shield for turning left and turning right maneuver type. Amin, H. J. [5] Computed critical gap by three most common techniques for 5 study location in Italy city. These techniques were maximum likely hood, Raff method and median method. [6] Used Logit model to compute critical gap of driver at unsignalized intersection. The same study has been conducted in Minnesota university by Arvind. M [7] in Minnesota City for 8 intersection. Report shows that three techniques has been used to estimate critical gaps for driver for left turning and right turning traffic. These techniques used were maximum likelihood, raff method and median method. Another study in America was conducted by Akhilesh and M. K [3] also uses maximum likelihood to estimate driver critical gap to accept the available headway. 


\section{Materials and Methods}

\subsection{Location of Study}

The study area is Adama city which is located in Ethiopia, Oromia national regional state, east Showa zone at a distance of $99 \mathrm{~km}$ from the capital city Addis Ababa. Adama city is located at $8.54^{\circ} \mathrm{N}$ and $39.27^{\circ} \mathrm{E}$. It is one of the reform cities in the region and consists of 14 urban and 4 rural Kebeles. With an area of 29.86square kilometers and a population density of $7,374.82 / \mathrm{km}^{2}$, all are urban inhabitants. Based on 2007 census, a total of 60,174 households were counted in the city, which results in an average of 3.66 persons to a household, and 59,431 housing units. According to INSA 131,000 parcel are there currently in Adama city administration. Here Study area has been shown on figure 1 .

\subsection{Traffic Condition}

Adama city (Nazareth) is one of the cities which have higher traffic characterized by being the junction of four main transport routes that connect to different parts of the country to Addis Ababa, to Djibouti/ Harar, to Wonji, to Arsi-Bale, Shashamene-Hawassa. The city has a big and strategic vision of being/to become a center of trade/commerce and conference for the whole Ethiopia, and the Oromia regional state in particular. Fortunately, the city is located at the center and nearby distances of natural tourist attractions, especially natural and historical tourist centers in Oromia regional state, South nation nationalities and people's regional state, including Afar and Harar regional state. In Adama city various road transportation like Carts, Bajaj, and Other vehicular and non-vehicular mode are visible. Road network in this city has both national and regional importance.

\section{STUDY AREA}
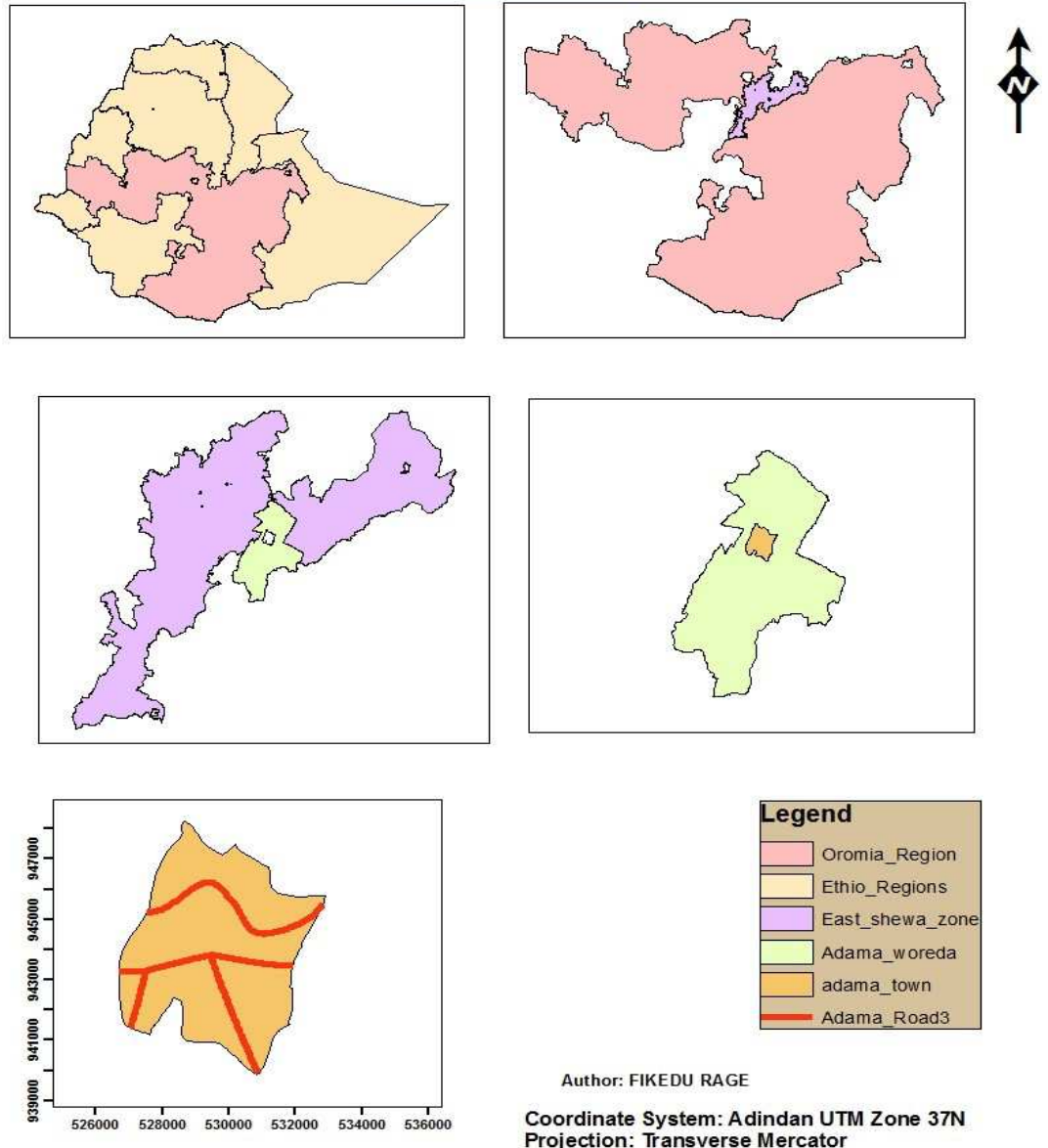

Author: FIKEDU RAGE

Coordinate System: Adindan UTM Zone 37N Projection: Transverse Mercator
Datum: Adindan Scale 1:150,000

Figure 1. Map of Study Area.

\subsection{Data Collection and Survey Method}

Collection and analysis of data were based up on selected intersection of Adama city. Three unsignalized intersection that were selected for this study were; Franko Intersection, Tikur Abay intersection and Wonji Mazoria intersection

\subsubsection{Headway}

Headway is defined as the time interval between two successive vehicles as they pass a point along the lane, also measured between common reference points on the vehicles. The average headway in lane directly related the rate of flow [8]. 


$$
v=\frac{3600}{H a}
$$

Where $\mathrm{v}=$ Rate of flow, Veh/h/ln

$\mathrm{Ha}=$ Headway in second.

There are various methods to collect the time headway of the vehicle moving on a street, Manual Method, Videographic techniques, Lever Mechanism, By Tape Recorder, Multiple Tap recorder. In order Improve accuracy, the data were collected by video graphic method by using digital camera. Video was recorded for $12 \mathrm{hrs}$. Starts from 7:00 am to 7:00 pm. Later data were extracted by using stop watch.
The vehicle arrivals were noted down by the observers. The difference of time arrivals between the two successive vehicles then gave the time headway between the two vehicles. The time gap also determined in the same way but it is taken only the time in which the first vehicle passing the reference and the time of arrival of the following vehicle. The stop watch was used to determine the time difference between the two incidents. Data collection was done vehicle categorize wise. Table 1 declares that Vehicle to vehicle interaction and abbreviation used.

Table 1. Vehicles Category with Assigned Symbols.

\begin{tabular}{|c|c|c|c|c|}
\hline Vehicle Category & Abbreviated & Back Vehicle & Front Vehicle & Assigned As \\
\hline Bajaj & $\mathrm{B}$ & Bajaj & Cart & $\mathrm{B}-\mathrm{Ca}$ \\
\hline Bus (Coach) & $\mathrm{Bu}$ & Bus (Coach) & Small Bus & $\mathrm{Bu}-\mathrm{SB}$ \\
\hline Car & $\mathrm{C}$ & Car & Truck & $\mathrm{C}-\mathrm{T}$ \\
\hline Pickup (4 Wheel Drive) & $\mathrm{P}$ & Pickup (4 Wheel Drive) & Truck-Trailer & P-TT \\
\hline Cart & $\mathrm{Ca}$ & Cart & Two Wheeler & Ca-TW \\
\hline Small Bus & SB & Small Bus & Bajaj & SB-B \\
\hline Truck & $\mathrm{T}$ & Truck & Bus (Coach) & $\mathrm{T}-\mathrm{Bu}$ \\
\hline Two Wheeler & TW & Two Wheeler & Pickup (4 Wheel Drive) & TW-P \\
\hline
\end{tabular}

\subsubsection{Road Geometry Measuring}

The road geometry of major and minor road has great influence on traffic flow characteristics like headway, speed, volume, delay on Intersection and gap accepting condition

Table 2. Geometric Characteristic in meters.

\begin{tabular}{|c|c|c|c|c|}
\hline Intersection Name & Major Road & & Minor Road & \\
\hline & Road Width & Shoulder Width & Road Width & Shoulder Width \\
\hline Franko & 12.4 & 1.2 & 11.6 & 1.2 \\
\hline Tikur Abay & 9.6 & 0.80 & 9.4 & 0.80 \\
\hline Wonji Mazoria & 12.0 & 1.00 & 9.6 & 1.00 \\
\hline
\end{tabular}

\subsection{Data Processing and Analysis}

Statistical Packages that were used in analysis of this study were SPSS Statistic 20 and Minitab. SPSS Statistic 20 was used fit best distribution model of headway and K-S technique was used for validation of model for headways in different flow ranges. Critical gap estimation and determining of headway distribution pattern of available gaps are aim of this study. After collection of headway, accepted and rejected gap, grouping of headways based on flow rate and vehicle to vehicle interaction. Estimation of best fit distribution and

Critical gap for left turning and right turning traffic using maximum likelihood method. Later validation of model was made by K-S and AD techniques. Figure 3 shows method of data analysis for this study.

\section{Result and Discussion}

This section includes investigation and detail of study, quantitative data analysis, development of models testing fitness (validation) was done for evaluation of critical gap for selected unsignalized intersection in Adama city.

\subsection{Headway Analysis}

The basic statistical properties headway on major road of selected intersections' range, minimum, maximum, mean and standard deviation was shown in Table 3. It is observed that average headways in seconds on major road are $5.58 \mathrm{sec}$, $8.42 \mathrm{sec}$ and $7.51 \mathrm{sec}$ for Franko, Tikur Abay and Wonji Mazoria intersection respectively. These numbers indicated the traffic at Franko intersection is densely populated on the road and Wonji Mazoria has less density compared to other intersection

Table 3. Statistical Properties of Headway per 15' in seconds.

\begin{tabular}{llllll}
\hline Intersection's & \multirow{2}{*}{ Ramge } & \multirow{2}{*}{ Minimum } & Maximum & \multicolumn{3}{l}{ Mean } \\
\cline { 5 - 6 } & & & Statistic & St.Dev \\
\hline Franko & 37.40 & .20 & 37.60 & 5.5803 & .22495 \\
Tikur Abay & 40.00 & .00 & 40.00 & 8.4297 & .29367 \\
W/Mazoria & 39.00 & .30 & 39.30 & 7.5156 & .28088 \\
\hline
\end{tabular}

Variation of basic statistical properties of headways for different flow rate ranges for three intersections has been shown on Table 4. Small headways indicate that traffic are moving in low speed (high flow rate). For three intersections the median values are less the average values of headways 
mean that $50 \%$ of vehicles are moving in time headways less than average values. Consider variance of headways for different flow rates greater variability is observed at low flow rate. It indicates that if flow of traffic is low (nearly congested) drivers selects the possible paths to go forward inconsistently. So that high fluctuation of headway is observed at low flow rate $(600-800 \mathrm{PCU})$ at Franko intersection.

Table 4. Statistical properties of Headway on major road PCU classes in seconds.

\begin{tabular}{|c|c|c|c|c|c|c|}
\hline Flow Range (PCU/Hr.) & Intersection & Minimum- & Maximum & Mean & Median & St. Dev \\
\hline \multirow[b]{2}{*}{$600-800$} & Franko & - & - & - & - & - \\
\hline & T/Abay & .66 & 38.30 & 12.6887 & 10.7000 & 9.33080 \\
\hline \multirow{3}{*}{$800-1000$} & Franko & - & - & - & - & - \\
\hline & T/Abay & .20 & 39.13 & 9.7087 & 6.6500 & 8.51863 \\
\hline & W/Mazoria & 1.11 & 39.89 & 16.5681 & 15.6000 & 9.23618 \\
\hline \multirow{3}{*}{$1000-1200$} & Franko & .60 & 26.09 & 10.7256 & 10.3900 & 7.46652 \\
\hline & T/Abay & .09 & 38.75 & 9.0592 & 5.7700 & 8.27516 \\
\hline & W/Mazoria & .71 & 36.13 & 12.0180 & 9.6000 & 9.13720 \\
\hline \multirow{3}{*}{$1200-1400$} & Franko & .35 & 37.60 & 8.7030 & 4.6050 & 8.94724 \\
\hline & T/Abay & .20 & 40.00 & 8.2329 & 4.7300 & 8.16933 \\
\hline & W/Mazoria & .29 & 111.46 & 10.5368 & 9.6000 & 12.13952 \\
\hline \multirow{2}{*}{$1400-1600$} & Franko & .23 & 31.43 & 5.8145 & 3.7600 & 5.58164 \\
\hline & W/Mazoria & .20 & 38.82 & 8.1054 & 5.5100 & 8.04629 \\
\hline \multirow{3}{*}{$1600-1800$} & Franko & .20 & 25.00 & 3.1384 & 2.5000 & 2.56290 \\
\hline & T/Abay & .20 & 31.80 & 5.7754 & 3.7700 & 5.56421 \\
\hline & W/Mazoria & .18 & 39.01 & 6.3713 & 4.6950 & 6.53948 \\
\hline \multirow{3}{*}{$1800-2000$} & Franko & .27 & 17.50 & 3.1636 & 1.8000 & 3.51868 \\
\hline & T/Abay & - & - & - & - & - \\
\hline & W/Mazoria & .78 & 17.84 & 3.5779 & 4.0150 & 2.63487 \\
\hline \multirow{3}{*}{$2000-2200$} & Franko & .40 & 2.70 & 1.3749 & 1.1800 & .81730 \\
\hline & T/Abay & - & - & - & - & - \\
\hline & W/Mazoria & .57 & 6.44 & 3.0069 & 2.8000 & 1.55189 \\
\hline
\end{tabular}

Type of vehicle to vehicle interaction study is another aspect of headway study which helps to show how headways are distributed among traffic categories for heterogeneous traffic condition. Table 5 shows that basic statistical characteristics headways based up type of vehicle to vehicle interaction. Vehicle interaction indicates combination of leader vehicle and follower vehicles. Driving characteristics and dimension of vehicle influences gap between leader and follower vehicle. 16 combination vehicle to vehicle interaction headway is collected for each intersection. Combination was selected based percentage vehicles in each stream. Car. Pickup, Truck and Small Bus has been selected for Franko intersection. The combination these vehicles can be Car-Car, Car-Pickup, Car-Truck, Car-Small Bus and else.

For Tikur Abay and Wonji Mazoria the task has been done. Based on collected data Car-Car interaction headway values is less than all combination for Franko intersection, Car-Bus for Tikur Abay intersection and Car-Pickup (4-wheel drive) for Wonji Mazoria intersection. Car-Car means both leading and follower is Car. Car-Pickup also can be defined as car follows pickup (4-wheel drive). The mean headways of Truck-Truck higher than all average values of the others combination. Consider the median of the headways $50 \%$ follower vehicles are approaches to leader vehicles less than average headways. The average values of headways observed at Tikur Abay intersection are higher than Franko and Wonji Mazoria intersection. This means Tikur Abay intersection traffic is sparse compared to other.

\subsubsection{Distribution of Headway for Different Flow Ranges}

To characterize and analyze variation in time headways for different flow ranges with an increment of 200PCU/Hr. was selected for this study. Six selected flow rates were [(600800), (800-1000), (1000-1200), (1200-1400), (1400-1600), (1600-1800), (1800-2000), (2000-2200)] PCU/Hr. Several probability densities were tested to identify best fitted distribution model for six flow ranges and the goodness of models were tested and validated by $\mathrm{K}-\mathrm{S}$ testing at $5 \%$ significance level. K-S values were computed as maximum difference between empirical and cumulative distribution function of time headways observed. If computed K-S value is greater than the critical K-S value, then the null hypothesis, which assumes the data follows a specified density function, is rejected. The main aim of this study is to insight the best fit time headway distributions for different flow ranges, by providing more information about variation in statistical parameters and testing these parameters at $95 \%$ confidence interval as changes in flow rates. This paper is also aimed to find out time headway distribution for three selected unsignalized intersection vehicles pairs as an aggregate. The Figures 4, 5 and 6 provides tested distribution in this study. 
PDF of Headway For Flow 12001400PCU/Hr

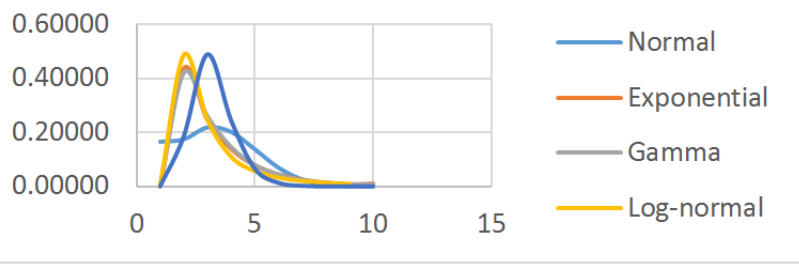

Figure 2. Tested Probability density function for Grouped Headways (a).

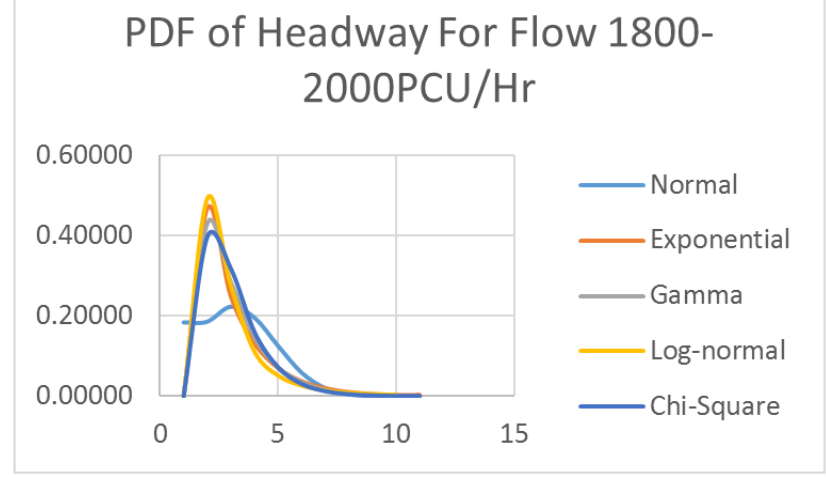

Figure 3. Tested Probability density function for Grouped Headways (b).

Table 6 shows best fit time headway distribution for different range of traffic flow in PCU/Hr. It is observed no headways data were collected flow rate between $(600-800$ and (800-1000) PCU/HR for Franko intersection and (600800) PCU/Hr. for Wonji Mazoria intersection. Based on best fitted distribution most of the driver's headway is lognormal distributed. It is indicated that for flow rate (1200-1400), (1400-1600) and (1800-2000) PCU/Hr. for Franko intersection, (1200-1800) for Tikur Abay and (1600-2000) for Wonji Mazoria intersection headways are log normally distributed. Gamma distribution is best fitted model for flow rate (600-800) for Tikur Abay, (100-1200) for both Tikur Abay and Franko intersection, (1600-1800) and (200022000) PCU/Hr. for Franko intersection.

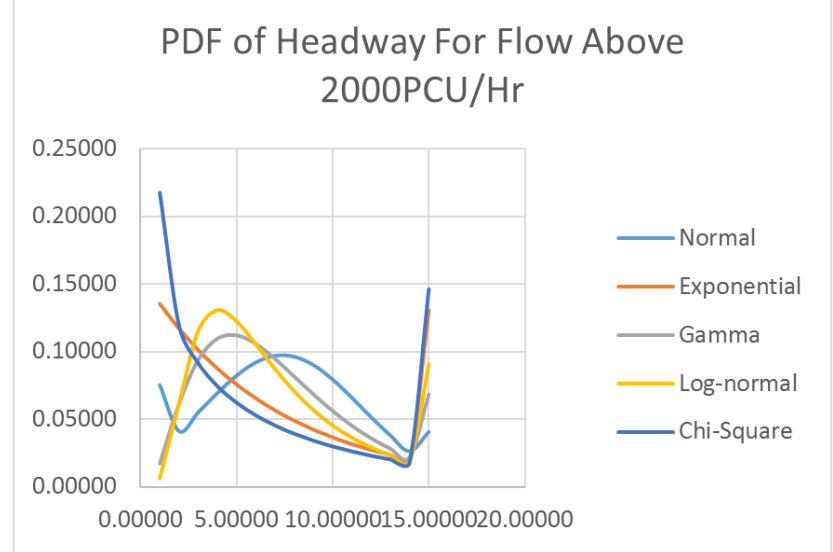

Figure 4. Tested Probability density function for Grouped Headways in seconds.

Table 5. Best fit headway distribution for different range of traffic flow.

\begin{tabular}{llll}
\hline Traffic Flow in PCU/Hr. & Franko Intersection & T/Abay Intersection & W/Mazoria Intersection \\
\hline $600-800$ & - & Gamma & - \\
$800-1000$ & - & Exponential & Normal \\
$1000-1200$ & Gamma & Exponential & Gamma \\
$1200-1400$ & Lognormal & Lognormal & Exponential \\
$1400-1600$ & Lognormal & Lognormal & Normal \\
$1600-1800$ & Gamma & Lognormal & Lognormal \\
$1800-2000$ & Lognormal & - & Lognormal \\
$2000-2200$ & Gamma & - & Normal \\
\hline
\end{tabular}

\subsubsection{Gap Acceptance}

Based on collected data headway (gap) accepted and rejected with respective waiting time to crossing or merging to major road were analyzed. In order to develop model of headway with factors that affect, knowing distribution pattern of headway is helpful to insight and identify relationship between headway and influencing parameters. So that, the function that fits cumulative frequency of observed headway (Probability distribution function) should be determined. AD test is statistical technique that was used to check the validity of model at 5\% significance level. This analysis to present good fit headway distribution for all type of traffic observed at study area and giving more understanding about characteristics of traffic flows on the corridor. The distribution depending up traffic condition like traffic flow speed and density. AD statistic was computed by Minitab19 with $95 \%$ CI the best fit selected based up test statistic and pvalue. Time headway distributions that were used as alternatives in this study were; Normal, Lognormal, 3PLognormal, Gamma, 3P-Gamma, Exponential and 2PExponential. From hypothesized distribution Table 5 shows that best fit distribution of available gaps are; 3P-Lognormal, 3P Gamma and Lognormal distribution for Franko, Tikur Abay and Wonji Mazoria intersection. And also for merging maneuver type Lognormal is best fit distribution for Franko intersection and 3P-Lognormal distribution for Tikur Abay and Wonji Mazoria intersection. By considering AD values and P- Values the researcher selected best distribution. AD is statistics that is used to test distribution. For a significance level of 0.05 the distribution which has small $\mathrm{AD}$ value or less than critical value as taken best distribution. Illustration: The null and the alternative hypothesis for goodness of fit are; 
H0: the data follow the specified distribution; and $\mathrm{H} 1$ : the data do not follow the specified distribution, Where $\mathrm{H} 0$ and H1 null and alternative hypothesis respectively. From seven hypothesized distributions for Franko intersection 3PLognormal distribution has been selected as first rank

Table 6. Summary of Goodness of Fit.

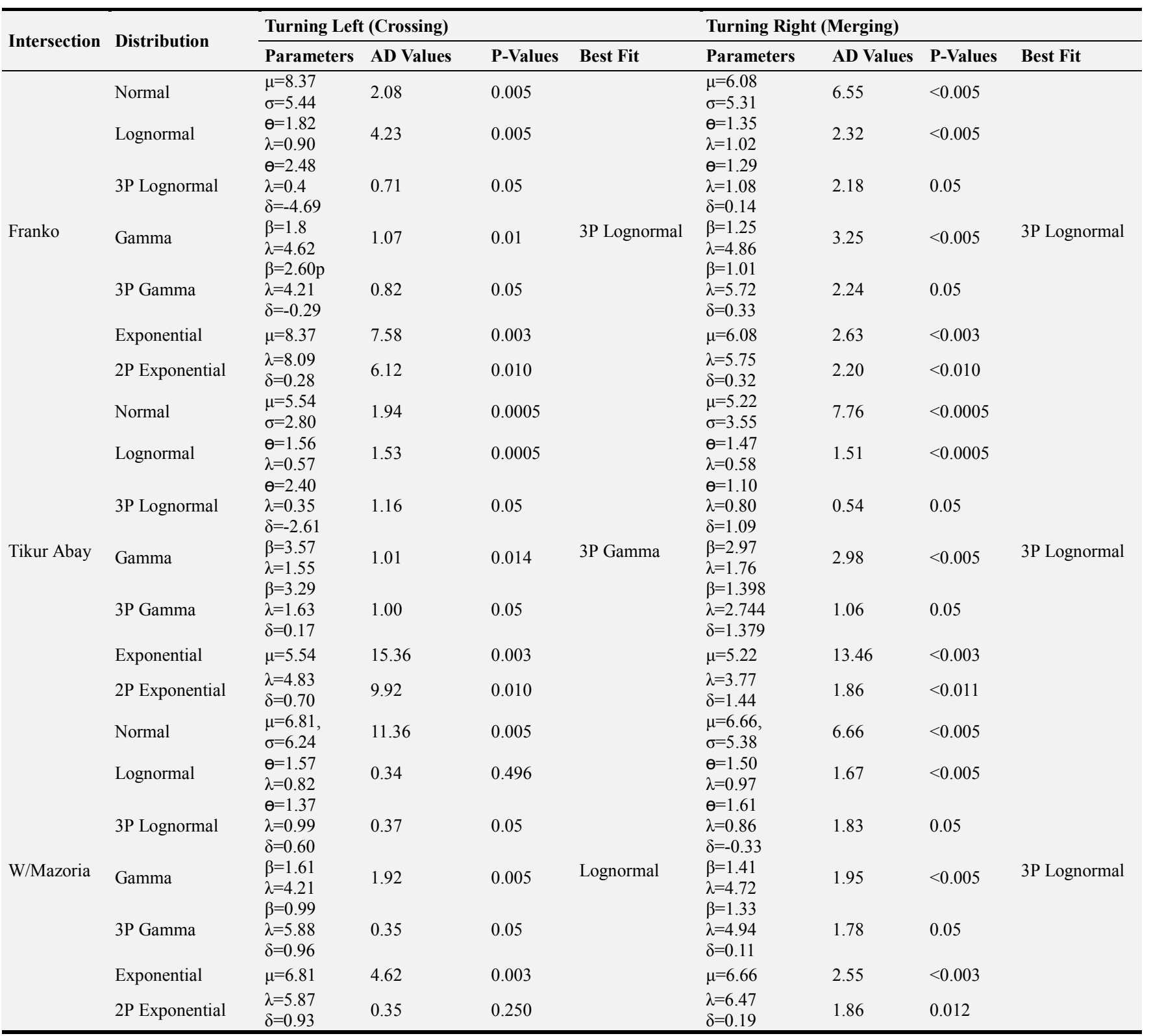

Note: $\mu$ (mean), $\sigma$ (St.Dev), $\Theta$ (location), $\beta$ (Shape), $\lambda$ (Scale) and $\delta$ (Threshold) are parameters used in testing goodness of fit

Table 7. Best fit Accepted and Rejected Gap distribution for Study Area.

\begin{tabular}{llllll}
\hline \multirow{2}{*}{ Distribution } & \multicolumn{2}{l}{ Kolmogorov Smirnov } & \multicolumn{2}{l}{ Anderson Darling } & \multicolumn{2}{c}{ Chi-Squared } \\
\cline { 2 - 6 } & Statistic & Rank & Statistic & Rank & Statistic \\
\hline Exponential & 0.15517 & 7 & 7.5735 & 7 & 39.503 \\
Exponential (2P) & 0.14212 & 6 & 6.0813 & 6 & 34.411 \\
Gamma & 0.07048 & 3 & 1.886 & 3 & 9.6535 \\
Gamma (3P) & 0.06252 & 2 & 0.81836 & 2 & 11.575 \\
Lognormal & 0.11147 & 5 & 4.2279 & 5 & 21.288 \\
Lognormal (3P) & 0.05102 & 1 & 0.07102 & 1 & 6.3458 \\
Normal & 0.08691 & 4 & 2.08 & 4 & 7 \\
\hline
\end{tabular}




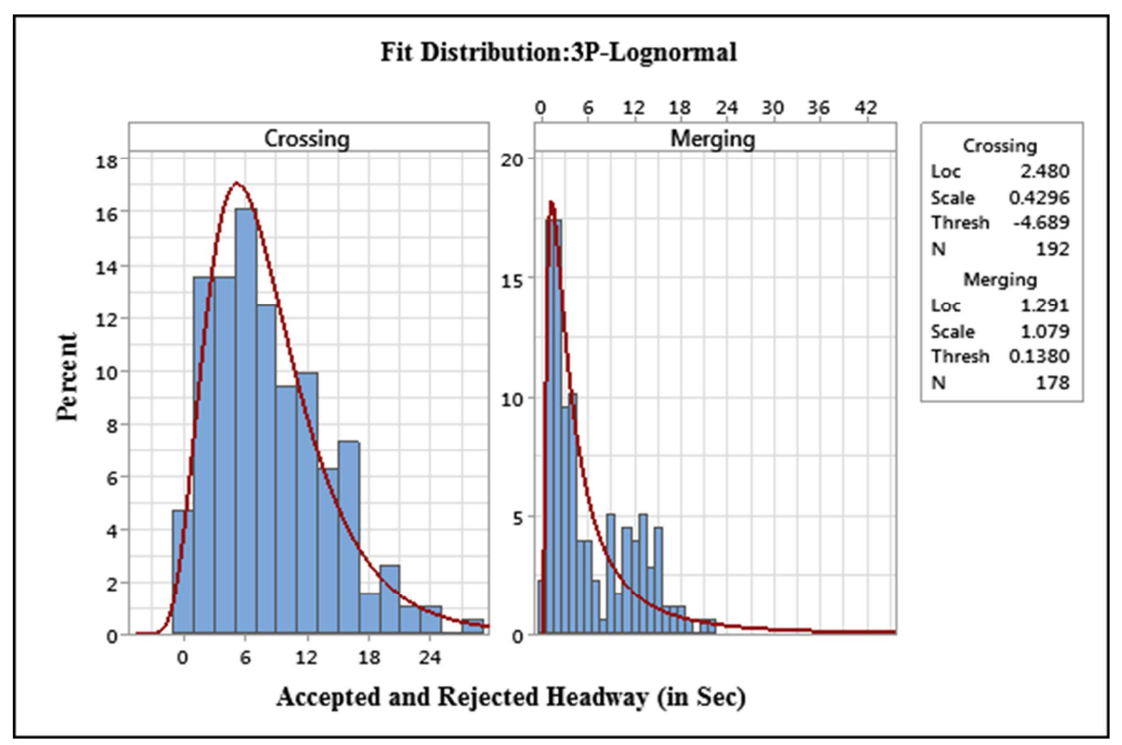

Figure 5. Fit Distribution of Headways of Franko Intersection.

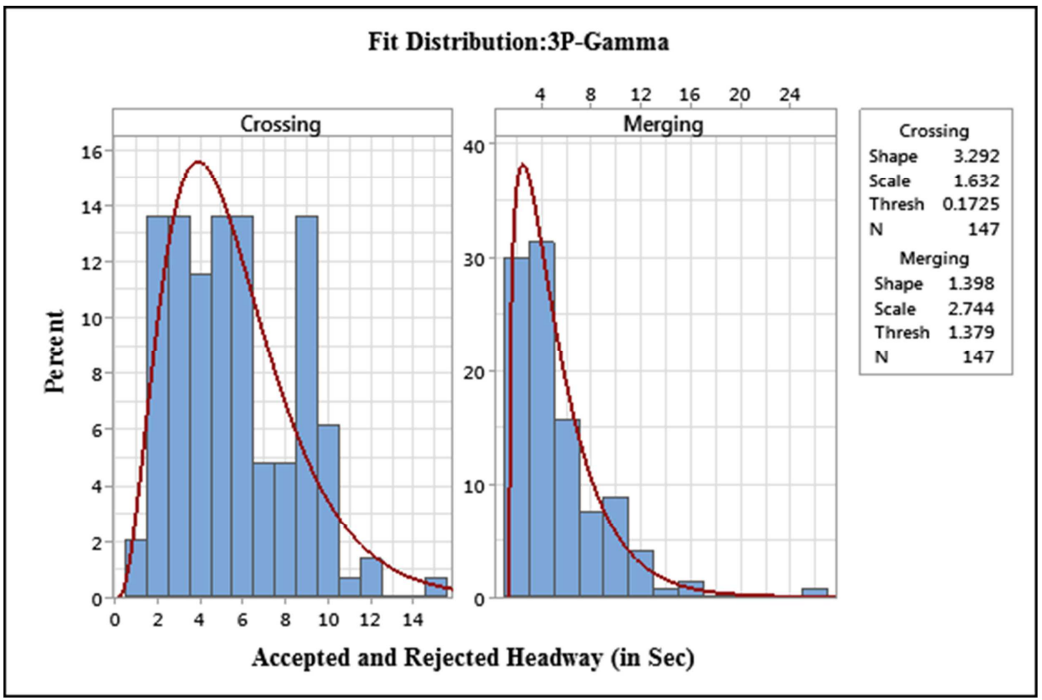

Figure 6. Fit Distribution of Headways of T/Abay Intersectio.

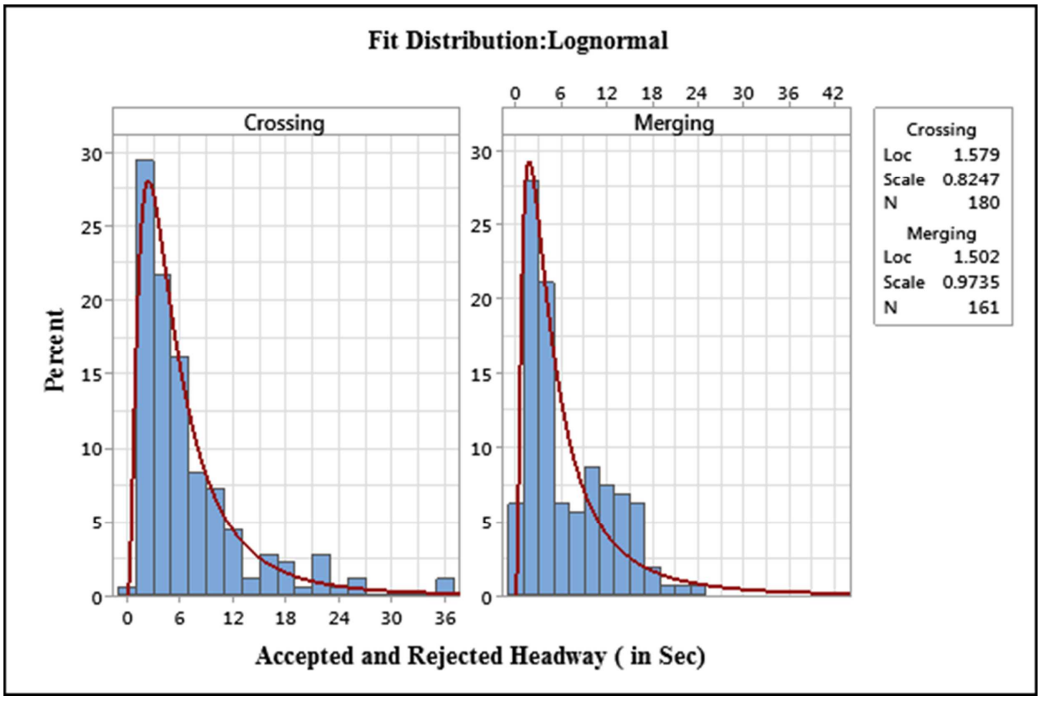

Figure 7. Fit Distribution of Headways of W/Mazoria Intersection. 
The standard deviation controls the spread of the distribution. A smaller standard deviation indicates that the data is tightly clustered around the mean; the distribution peak values is taller. A larger standard deviation indicates that the data is spread out around the mean; the distribution curve flatter and wider.

The peak values show variance which indicates that how the data distribution are more concentrated to mean values or not. Basic statistical characteristics of waiting time for two maneuver types (merging and crossing) has been shown by in the Table 8 . Consider average waiting time of minor road vehicles to cross and merge to major road, the vehicles that are merging to major road have less waiting time means drivers uses even available less gaps compared to these drivers who are crossing the major road and turning to the right.

Table 8. Statistical Properties of Waiting Time for with maneuver type in seconds.

\begin{tabular}{llllll}
\hline \multirow{2}{*}{ Intersection's } & Minimum & & Maximum & & \multicolumn{2}{c}{ Mean } \\
\cline { 2 - 6 } & Crossing & Merging & Crossing & Merging & Crossing \\
\hline Franko & 1.00 & .00 & 25.85 & 12.87 & 10.54 \\
T/Abay & .06 & .27 & 23.20 & 19.91 & 12.38 \\
W/Mazoria & 1.04 & .00 & 19.72 & 14.27 & 9.88 \\
\hline
\end{tabular}

As per collected data average waiting time for merging maneuver are $6.46 \mathrm{sec}, 11.12 \mathrm{sec}$ and $6.70 \mathrm{sec}$ for Franko, Tikur Abay and Wonji Mazoria intersection respectively. And also for traffic turning the right, 10.54, 12.38, and $9.88 \mathrm{sec}$.

Table 8 provides that distribution fit for waiting time on minor road for both left turning and right turning drivers. It has been shown that lognormal distribution is selected for the left turning drivers. And also for the merging to major road 3P-Gamma distribution is best fit to explain distribution of waiting time. Non parametric K-S test was used to test and validated estimated model at $95 \%$ confidence interval.

\subsection{Critical Gap Estimation}

As per literature review most common methods used by many researchers in determination of critical gap were: Maximum likelihood method, Raff method, Green shield method, The Lag method, Harder's method, Logit method, and Wu's Method. In this study Maximum likelihood method was used in estimation of critical gap for drivers for selected unsignalized in Adama city. The maximum likelihood method of estimating critical gap is based on the fact that a driver's critical gap is between the range of his largest rejected gap and his accepted gap [9]. Density function distribution for the critical gaps must be assumed between the largest rejected gap and accepted gap and used a lognormal distribution for the critical gaps. This distribution is skewed to the right and has non-negative values, as would be expected in these circumstances. Drivers that are turning to right and turning to left from minor road have different critical gaps. In this paper two cases have been studied were critical gap for merging to major road and crossing major road turn to left be estimated separately by maximum likelihood method. As Dutta, M. M. [10] forwarded the parameters of distribution function of the critical gaps, the mean $(\mu)$ and variance $(\sigma 2)$, are obtained by maximizing the likelihood function.

$$
\mathrm{L}=\prod_{i=1}^{n}[F(a i)-F(r i)]
$$

Where, $\mathrm{L}=$ maximum likelihood function, ai=logarithm of the accepted gap of driver $\mathrm{i}$, ri=logarithm of the maximum rejected gap of driver $\mathrm{i}, \mathrm{F}$ (ai) and $\mathrm{F}(\mathrm{ri})=$ cumulative distribution functions for the normal

Distribution of accepted and rejected gap respectively

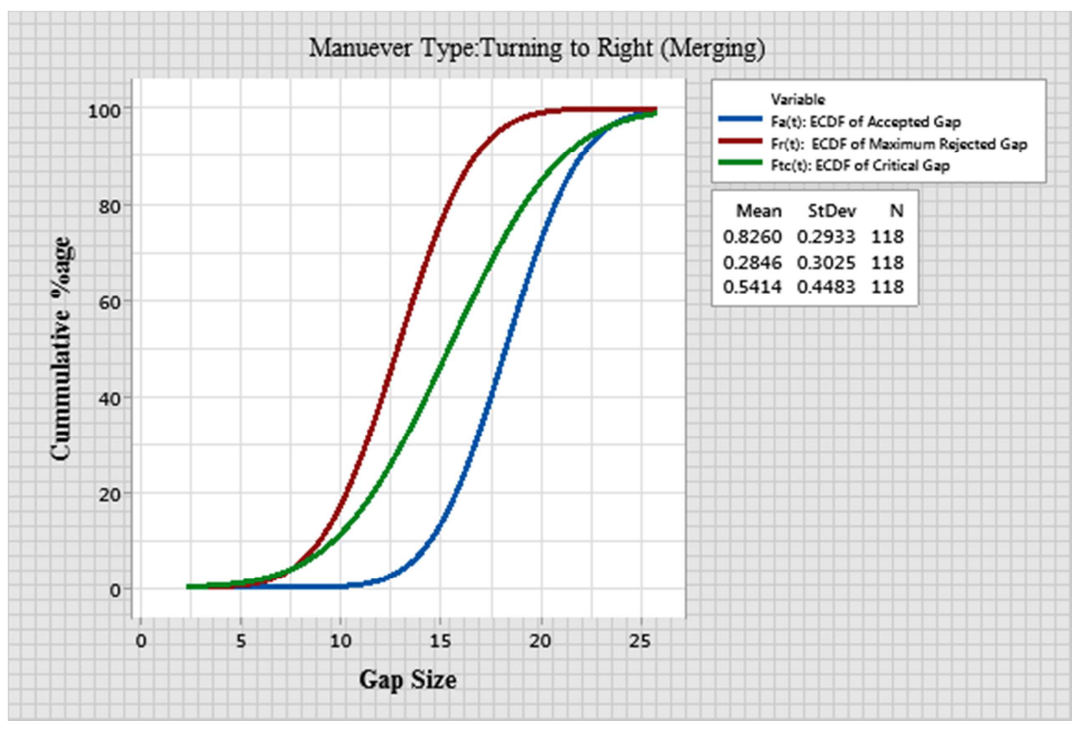

Figure 8. Empirical Cumulative Distribution Function (ECDF) of Gaps of Franko. 
Table 9. Estimated Maximum Likelihood Parameters and Critical Gaps.

\begin{tabular}{llllll}
\hline Intersection & Maneuver Type & Mean & St.Dev & Std. $^{2}$ & E(tc) \\
\hline Franko & Crossing & 0.71 & 0.10 & 0.01 & 5.17 \\
& Merging & 0.69 & 0.15 & 0.02 & 5.03 \\
T/Abay & Crossing & 0.63 & 0.11 & 0.01 & 4.32 \\
& Merging & 0.57 & 0.13 & 0.02 & 3.79 \\
W/Mazoria & Crossing & 0.59 & 0.14 & 0.02 & 3.96 \\
& Merging & 0.68 & 0.14 & 0.02 & 4.88 \\
\hline
\end{tabular}

Empirical cumulative distribution function of accepted, maximum rejected and critical gap at Franko intersection has been shown on Figure 8. The critical gap distribution is between accepted gap and maximum rejected gap. It has been observed that $50 \%$ of accepted gap for the traffic that are

Turning to left (crossing) are less than $18 \mathrm{sec}$ and that of rejected gap is less than $15 \mathrm{sec}$. All gaps accepted or rejected as per data collected for major stream of Tikur Abay is less than 40 sec.

Estimated critical gaps for unsignalized intersection has been shown on the Table 10. These values can bes used directly in determination of capacity and delay. It is observed that critical gaps available for drivers at Tikur Abay intersection is least in both manuver type. This shows that the driver uses more gaps to cross and merge to major road. Critical gap at Franko intersection for the drivers that are crossing major roads is largest estimated values which is $5.17 \mathrm{sec}$. Critical gap has been estimated by equation of;

$\mathrm{E}(\mathrm{tc})=e^{\mu+0.5 \sigma}$, where, $\mathrm{E}(\mathrm{tc})$ : Expected critical mean, $\mu$ and $\sigma$ are parameters of normal distribution of PDF of $f(a i)$ and $\mathrm{f}(\mathrm{ri})$ and ai and ar is logarithmic value of accepted and rejected gaps respectively.

Table 10. Estimated Critical Gap for Traffic Turning to the Left and Right.

\begin{tabular}{|c|c|c|c|c|c|c|c|}
\hline \multirow{2}{*}{ Intersection } & \multirow{2}{*}{$\begin{array}{l}\text { Opposing } \\
\text { Volume }\end{array}$} & \multirow{2}{*}{$\begin{array}{l}\text { Minor Road } \\
\text { Volume }\end{array}$} & \multirow{2}{*}{$\begin{array}{l}\text { Speed (in } \\
\text { kmph) }\end{array}$} & \multicolumn{2}{|c|}{ Waiting Time (in sec) } & \multicolumn{2}{|c|}{ Estimated Critical gap } \\
\hline & & & & Crossing & Merging & Crossing & Merging \\
\hline Franko & $1,157.00$ & 881.00 & 30.00 & 12.67 & 7.54 & 5.17 & 5.03 \\
\hline T/Abay & $1,233.00$ & 606.00 & 30.12 & 8.36 & 14.81 & 4.32 & 3.79 \\
\hline W/Mazoria & $1,531.00$ & $1,110.00$ & 28.70 & 7.44 & 8.69 & 3.96 & 4.88 \\
\hline Average & & & & & & 4.56 & 4.48 \\
\hline
\end{tabular}

\section{Discussion}

Headway distribution is important in traffic modelling and simulation. Several studies have been conducted on headway distribution under heterogeneous traffic conditions. Arrival patterns and direction of turning affects distribution of headway. This study revealed headway distribution for different ranges of flow rates for selected unsignalized intersection in Adama city. It is observed that Gamma and exponential distribution were found to be best model for low traffic flow level which is $600-1200 \mathrm{PCU} / \mathrm{Hr}$. And also from moderate to higher flow rate (1200-2500) PCU per hour lognormal distribution was found appropriate model in this paper. This finding is similar with the study conducted in India in Assam by Farah et al., H [11] and in Mumba AlObaedi, J. i by [4]. Another study that has been conducted in India by Abhishek, O., \& Marko A. A. Boon, R.-Q [2] showed that log-logistic and normal distribution were found best model at moderate flow level and Pearson distribution for peak state flow. Difference of selected distributions may arise due to traffic flow condition and ranging of traffic flow rate from countries to countries.

One important parameter of traffic flow characteristic focused in this study was critical gap. By using maximum likelihood method driver's critical gaps for selected intersection of Adama city has been estimated. The current study found that the critical gap of left turning drivers are $5.17,4.32$ and 3.96 seconds for flow rates of 1100,1300 and $1500 \mathrm{PCU} / \mathrm{Hr}$. respectively. For the driver that merging to major road estimated critical gaps were 5.03, 3.79 and 4.88 seconds for stated traffic flow rates. Average estimated critical gap for left turning in this study is $4.56 \mathrm{sesc}$ and for right turning vehicles is found to be $4.48 \mathrm{sec}$. The same study has been conducted in Malaysia by Gavulova, A. Gavulova, A [12] which is revealed critical gap for left turning drivers has been found to be $3.3 \mathrm{sec}$ and $4.2 \mathrm{sec}$ for right turning vehicles. Thus it seems possible that, these results could be due to the fact that as the flow rate increase critical gap of drive leads to decrease. Another's similar studies that has been conducted in different countries has been shown in the Table 11 .

Table 11. Comparison of Estimated Critical by different Authors.

\begin{tabular}{|c|c|c|c|c|c|}
\hline \multirow{2}{*}{ Paper/Author Name } & \multirow{2}{*}{ Major Road Lane } & \multirow{2}{*}{ Average Speed } & \multicolumn{3}{|c|}{ Critical gaps (in Sec) } \\
\hline & & & Left Turn & Right Turn & Average \\
\hline This study/2020 & 2 & $30 \mathrm{kmph}$ & 4.56 & 4.48 & 4.52 \\
\hline \multirow{2}{*}{ Wan Hashim/2007 } & 1 & Base value & 4.0 & 3.30 & 3.6 \\
\hline & Multilane & & 4.20 & 3.30 & 3.72 \\
\hline \multirow{2}{*}{$\mathrm{HCM} / 2010$} & 2 & Base value & 7.1 & 6.2 & 6.65 \\
\hline & 4 & Base value & 7.5 & 6.5 & 7.20 \\
\hline (Andyka et al./2011 & 2 & $33 \mathrm{kmph}$ & 3.29 & 3.58 & 3.43 \\
\hline
\end{tabular}

See that above Table 11 critical gap for merging traffic is 4.48 and for crossing major road 4.56. It is close to that of
$[15,6]$ and [16] studies. This may be shows the similarities of traffic flow characteristic with this area of study. 
Discrepancies of this study and other study has been also shown on the Table 11 Critical headway (gaps) of developed country like America which is mentioned in R. Morris, M. [14] are different from that of developing country. For example, study done by Gavulova, A. [12] in Malaysia is more similar with this study. In general, the critical gaps need to merge or turning right is less than that of turning left.

\section{Conclusion and Recommendation}

\subsection{Conclusion}

This paper presents a detail study of available headway distribution, waiting time characteristics of unsignalized intersection under mixed traffic condition and weak lane disciplined urban unsignalized intersection.

Among hypothesized models lognormal distribution selected and validated for higher flow rate like Franko intersection and Gamma distribution is best fit for low flow rate like Tikur Abay Intersection. By considering two alternatives turning left (crossing) and turning right (merging to major road) in determination drivers critical gap estimation were done.

For the drivers who are turning to right computed critical gaps for Franko, Tikur Abay and Wonji Mazoria intersection were $5.17 \mathrm{sec}, 4.32 \mathrm{sec}$ and $3.96 \mathrm{sec}$ respectively.

And also the waiting time of drivers that are turning to left for three selected intersections were about $26 \mathrm{sec}, 24 \mathrm{sec}$ and $20 \mathrm{sec}$. From the developed nonlinear model traffic turning to left moving with average speed $30 \mathrm{kmph}$, average headway of $10 \mathrm{sec}$ and minor road traffic volume $2000 \mathrm{PCu} / \mathrm{Hr}$., increasing $25 \%$ major road traffic volume makes to double waiting time on minor road. Increasing major road traffic volume by $50 \%$ makes to quadruple waiting time.

For low flow rates less than 500PCU/Hr., average speed of $20 \mathrm{kmph}$ and large headway more than $25 \mathrm{sec}$ waiting time not more affected by traffic volume on major road. For the turning to right the minor road volume has high influence on waiting time. Generally Safe crossing of vehicles and merging of vehicles from minor road to major road, for the lane width less than $3.6 \mathrm{~m}$ and the traffic volume on the major road should not be more than 2200PCU/Hr. and the critical headway on the major road should not be less than $4.56 \mathrm{sec}$ and $4.48 \mathrm{sec}$ respectively.

\subsection{Recommendation}

In this paper Headway distribution and critical gaps for drivers has been estimated. And also waiting for characteristics of drivers to accept or reject gaps has been investigated. For forthcoming researchers and professionals, the author of this paper recommended the following areas of study related to this investigation for forthcoming researchers.

1) Influence of driver's behavior (i.e. aggressiveness, drugs and alcoholic, age, gender on gap acceptance at unsignalized intersection.

2) Influence of distress like rutting, potholes etc. on gap acceptance at unsignalized intersection.
3) Impact of topography and geometric layout of intersection on gap acceptance at uncontrolled intersection.

4) Skid resistance and surface deflection on gap acceptance at uncontrolled intersection under mixed traffic condition.

For drivers and road users:

a) Drivers shouldn't take gaps less suggested critical of $4.36 \mathrm{sec}$ for left turning and 3.79 for right turning.

b) Pedestrians should use their facilities to cross or to merge to major road

For Policy makers and Professional

a) They should prepare guideline which gives more understanding for driver and road users

b) Properly regulate traffic to reduce waiting time by posting, speed limit less than $30 \mathrm{kmph}$, critical gap greater than suggested $(3.79 \mathrm{sec})$, installation of signal specially on Tikur Abay intersection.

\section{References}

[1] Abd-Elaziz, A., \& Abd-Elwahab, S. (2017). The Effect of Traffic Composition on PCU Values and Traffic Characteristics on The Northern Arc of The first Ring Road around Greater Cairo. IOSR Journal Of Humanities And Social Science (IOSR-JHSS), 01-17.

[2] Abhishek, O., \& Marko A. A. Boon, R.-Q. (2017). A singleserver queue with batch arrivals and semi-Markov services. Queueing Syst, 217-240.

[3] Akhilesh et al., M. K. (2014). Study on Speed and Time-headway Distributions on Two-lane Bidirectional Road in Heterogeneous Traffic Condition. 11th Transportation Planning and Implementation Methodologies for Developing Countries, 428-438.

[4] Al-Obaedi, J. (2016). Estimation of Passenger Car Equivalents for Basic Freeway Sections at Different Traffic Conditions. World Journal of Engineering and Technology, 1-17.

[5] Amin, H. J. (2015). A review of Estimation approaches at uncontrolled intersection in case of heterogeneous traffic conditions. 5-9.

[6] Andyka, K., \& Haris, N. (2011). Critical Gap Analysis of Dual Lane Roundabouts. Procedia Social and Behavioral Sciences, 709-717.

[7] Arvind et al., M. (2008). Macroscopic Review of Driver Gap Acceptance and Rejection Behavior in the US - Data Collection Results for 8 State Intersections. Minessota: Intelligent Transportation Systems Institute.

[8] Bartin et al., O. (2017). Simulation of Vehicle ' Gap Acceptance Decision Using Reinforcement Learning. Uludağ University Journal of The Faculty of Engineering, 161-178.

[9] Doddapaneni et al., A. (2017). Multi Vehicle-Type Right Turning Gap Acceptance and Capacity Analysis at Uncontrolled Urban Intersections. Periodica Polytechnica Transportation Engineering, 1-9.

[10] Dutta, M. M. (2018). Gap acceptance behavior of drivers at uncontrolled T-intersections under mixed traffic conditions. Journal of Modern Transportation, 119-132. 
[11] Farah et al., H. (2009). A passing Gap Acceptance model for two lane rural highway. Transportmetrica, 159-172.

[12] Gavulova, A. e. (2012). Use of statistical techniques for critical gaps Estimation. "Reliability and Statistics in Transportation and Communication" (pp. 20-26). Zillina: Transport and Telecommunication Institute.

[13] Maurya, A. (2015). Speed and Time headway Distribution Under Mixed Traffic Condtion. Journal of Eastern Asia Society for Transportation Studies, 1-19.
[14] R. Morris, M. (2010). Highway Capacity Manual (Vol. I). Washington DC: Transportation Research Board Committee.

[15] Wan Ibrahim, W. (2007). Estimating Critical Gap Acceptance For Unsignalized T-Intersection Under Mixed Traffic Conditions. Procedings of Eastern Asia Society For Transportation Studies, 2-13.

[16] ZongZhong et al., T. (1999). Implementing the maximum likelihood methodology to measure a driver's critical gap. Transportation Research Part A 33, 187-197. 